\title{
Editorial: Paleoceanography
}

Markus Kienast ${ }^{1}$ and Jean Lynch-Stieglitz ${ }^{2}$

1Department of Oceanography, Dalhousie University, Canada; Markus.Kienast@dal.ca

${ }^{2}$ School of Earth and Atmospheric Sciences, Georgia Institute of Technology, Atlanta, USA; jean@eas.gatech.edu

The ocean covers $70 \%$ of the Earth's surface, contains 55 times more $\mathrm{CO}_{2}$ than the atmosphere and redistributes heat at a rate comparable to the atmosphere. Understanding the ocean's role in past climate change is thus of fundamental importance for understanding past (and future) global changes.

This PAGES special newsletter section highlights recent advances in paleoceanography. Many of these studies were presented in one form or another at the 9th International Conference on Paleoceanography (ICP9), which took place in September 2007 in Shanghai, China. This meeting was convened as a tribute to Sir Nicholas Shackleton, who was instrumental in developing not only the field of paleoceanography but also the tradition of this triennial meeting and the strong international community it represents. It seems fitting not only to reflect on the contributions of this community over the decades since the first ICP in 1983 but also on the prospects for further influence in the near- and long-term future.

From the outset, paleoceanographers have made fundamental contributions to our understanding of oceanography, climatology and biogeochemistry. The continuous nature of the deep sea record allowed for a better understanding of the history of Quaternary ice-volume changes and their relationship to orbital forcing. Maps of ice age temperatures (CLIMAP) provided the quantitative boundary conditions necessary for the first paleoclimate simulations in general circulation models. Reconstructions of deepwater properties demonstrated that deepwater flow patterns might not have been as stable as previously thought, and were likely involved in glacial-interglacial changes in atmospheric $\mathrm{CO}_{2}$. Similarly, geochemical and faunal records of algal productivity pointed to time-varying efficiency of the biological sequestration of atmospheric $\mathrm{CO}_{2}$ into the ocean's interior.

More recently, paleoceanographic studies have been uncovering the mechanisms behind the abrupt changes in climate and greenhouse gas concentrations, as revealed in the ice core records from Greenland and Antarctica. Newly developed and refined proxy methods and targeted coring, much of it coordinated within the IMAGES and IODP programs, are now enabling (semi-)quantitative reconstructions of the cause, nature and extent of rapid changes in ocean circulation (see highlights by Boessenkool, Lynch-Stieglitz, Gherardi, Schmidt) and its linkage with atmospheric circulation patterns (Grimalt, Weldeab, Yamamoto, Kaiser) and deep ocean $\mathrm{CO}_{2}$ reservoirs (Galbraith) on timescales ranging from millennial to annual. New approaches to reconstructing past changes in sea level challenge the traditional view of very slow ice-sheet growth during the glacial period and rapid loss during the glacial termination (Siddall).

Increasingly, the paleoclimate community is contributing to our understanding of future climate change. Paleoceano- graphic data and modeling are being used to explore the sensitivity of the ocean/ climate/biology systems to increased $\mathrm{CO}_{2}$. The Late Paleocene-Eocene Thermal Maximum 55 Myr ago (Sluijs) provides a view of the chemical, biological and climatic consequences of adding a large amount of carbon to the ocean-atmosphere system. Pushing our reconstructions of $\mathrm{CO}_{2}$ beyond the limit of ice core records (Hönisch) will also be crucial to our ability to assess climate sensitivity.

Paleoclimate data are being used to test the models that are used for future climate prediction and provide the context to better understand the magnitude of anthropogenic changes relative to natural variability. We, as data-generating paleoceanographers, are being challenged by modelers and climate dynamicists to make more quantitative reconstructions of ocean and climate variables, and to provide error bars along with these measurements. We are also being asked to do a better job of synthesizing our results in a way that they can be readily used and understood by non-specialists. This will mean some adjustments in the way we have always worked and will also require similar adjustments on the part of our new collaborators outside of the paleo-realm (e.g., explicitly modeling paleoceanographic proxies). We look forward to seeing the advances this will bring to paleoceanography and our understanding of the Earth System in the coming decades.

\section{PAGES Calendar 2008}

05 - 07 March 2008 - Boulder, USA

$38^{\text {th }}$ Annual International Arctic Workshop

Associated Meeting: 8 March 2008 -

(2) PAGES Arctic 2k Workshop

http://instaar.colorado.edu/meetings/AW2008/

20 - 26 April 2008 - Piran, Slovenia

ESF EuroCLIMATE Spring School -

"Late Quaternary timescales and chronology"

www.pages-igbp.org/calendar/calendar08.html\#AnchorApril

\section{6 - 28 March 2008 - Zürich, Switzerland \\ "Radiocarbon and Archaeology" \\ $5^{\text {th }}$ International Symposium \\ www.c14archaeology.ethz.ch/}

05 - 09 May 2008 - Cape Town, South Africa $4^{\text {th }}$ IGBP Congress: Sustainable Livelihoods in a Changing Earth System www.igbp2008.co.za/

\section{6 - 29 May 2008 - Louvain-La Neuve, Belgium Climate Change: From Geologic Past to Uncertain Future \\ www.uclouvain.be/en-berger2008.html}
29 June - 03 July 2008 - Fairbanks, USA $9^{\text {th }}$ International Conference on Permafrost www.nicop.org/

